\title{
Materiais cerâmicos: uma revisão sistemática sobre desgaste e longevidade
}

\author{
Ceramic materials: a systematic review about wear and longevity
}

\author{
Francisco Francislan Gomes da Silva', João Wendell Maia Magalhães', \\ Manasses Tercio Vieira Grangeiro', Viviane Maria Gonçalves de Figueiredo \\ 'Graduando em Odontologia. Faculdade de Odontologia, Centro Universitário Leão Sampaio. Juazeiro do Norte, Ceará, Brasil. \\ francislangomes@hotmail.com, wendell_magalhaes01@hotmail.com, terciomanasses@gmail.com \\ ${ }^{2}$ Autora para correspondência. Doutora em Prótese Dentária. Docente na Faculdade de Odontologia, Centro Universitário Leão Sampaio. \\ Juazeiro do Norte, Ceará, Brasil. vivi_mfigueiredo@yahoo.com.br
}

Resumo | Introdução: Os materiais cerâmicos nas últimas décadas, apresentaram um grande avanço microestrutural para atender os quesitos funcionais e estéticos, a fim de aumentar a longevidade das reabilitações orais. Porém, o desgaste acentuado do esmalte dental tem colocado em dúvida as indicações e aplicação de materiais cerâmicos para o restabelecimento estético e funcional dental. Objetivo: Investigar, por meio de uma revisão sistemática da literatura, o desgaste de diferentes materiais restauradores e o elemento dental antagonista, frente à longevidade do uso clínico. Material e método: A presente revisão sistemática foi realizada por busca de artigos científicos dos anos de 2006 a 2016, nas seguintes bases de dados: Bireme, Pubmed e Scielo, utilizando-se as palavras-chave: cerâmica, desgaste dental e longevidade. Resultado: Dos estudos revisados obteve-se 13 artigos científicos, com base no grau de evidência científica apresentou-se $84,62 \%(n=11)$ dos estudos em nível 3 e 15,38\% ( $n=2)$ são de nível 8 . Os estudos revisados apresentavam diferenças de métodos laboratoriais, o que faz com que dificulte a discussão dos achados. Conclusão: $O$ desgaste do elemento dental antagonista (esmalte) parece ser maior quando utiliza-se uma cerâmica ácido-sensível; já quanto a longevidade, o dissilicato de lítio apresenta a maior perda de material.

\begin{abstract}
Introduction: The ceramic materials in the last decades, presented a great microstructural advance to meet the functional and aesthetic requirements, in order to increase the longevity of ceramic oral rehabilitations. However, the accentuated wear of the dental enamel has checked the indications and application of ceramic materials. Objective: To investigate the wear of different restorative materials and the antagonistic dental element, against the longevity of clinical use through a systematic review. Material and method: The present systematic review was carried out by search of scientific articles from the years 2006 to 2016, in the following databases: Bireme, Pubmed and Scielo, using the keywords: ceramic, dental wear and longevity. From the reviewed 13 articles, based on the degree of scientific evidence, $84,62 \%$ ( $n=$ $11)$ of the studies at level 3 and $15,38 \%(n=2)$ are of level 8. Result: The reviewed studies presented differences of laboratory methods, which makes it difficult to discuss the results. Conclusion: The wear of the dental element antagonist (enamel) seems to be greater when an acidsensitive ceramic is used; as for longevity the lithium disilicate presents the greatest loss of material.
\end{abstract}

Keyword: Ceramic; Dental Wear; Longevity.

Palavras-chave: Cerâmica; Desgaste dental; Longevidade. 


\section{Introdução}

Com a evolução da Odontologia adesiva, apelo estético e social cada vez mais presente, e as inovações tecnológicas como o processo de Computer Aided Design and Computer Aided Manufacturing (CAD-CAM), ou seja, Desenho assistido por computador -Manufatura assistida por computador, as restaurações livres de metal tornaram-se mais solicitadas no tratamento reabilitador.

Assim, houve a necessidade de melhorar as propriedades mecânicas, estéticas e adesivas destes materiais, ou seja, os materiais cerâmicos nas últimas décadas apresentaram um grande avanço microestrutural para atender os quesitos funcionais e estéticos, a fim de aumentar a longevidade das reabilitações orais cerâmicas.

Os sistemas cerâmicos apresentam resultados satisfatórios para a restaurações livres de metal de acordo com Della Bona, Kelly', porém o desgaste acentuado do esmalte dental tem colocado em dú- vida as indicações e aplicação de materiais cerâmicos para o restabelecimento estético e funcional dental $^{2,3}$.

Com base na problemática abordada, decorrente da escassez de estudos e relatos deste tema na literatura, objetiva-se realizar uma revisão sistemática sobre o desgaste de diferentes materiais restauradores e o elemento dental antagonista, frente à logenvidade do uso clínico.

\section{Metodologia}

A presente revisão sistemática sobre cerâmicas odontológicas enfocando principalmente desgaste e longevidade será detalhada a seguir:

\section{Bases de Dados}

As bases de dados utilizadas nesta revisão são descritas na TABELA 1.

Tabela 1. Descreve as bases de dados e os respectivos sites, que foram utilizados na busca textual.

\begin{tabular}{|c|c|}
\hline Base de Dados & Sites \\
\hline Bireme & http://bvsalud.org/ \\
\hline Scielo & http://www.scielo.org/php/index.php \\
\hline Pubmed & http://www.ncbi.nlm.nih.gov/pubmed \\
\hline
\end{tabular}

\section{Palavras ou Termos Chaves}

As palavras-chaves foram buscadas no Decs Saúde e Mesh, sendo assim selecionadas as seguintes: Cerâmica (Ceramic), Desgaste Dental (Tooth Wear), Longevidade (Longevity).

\section{Critérios de Inclusão e Exclusão dos Artigos}

Os critérios de inclusão e exclusão dos artigos científicos para esta revisão sistemática são apresentados na imagem (FIGURA. 1) a seguir. 


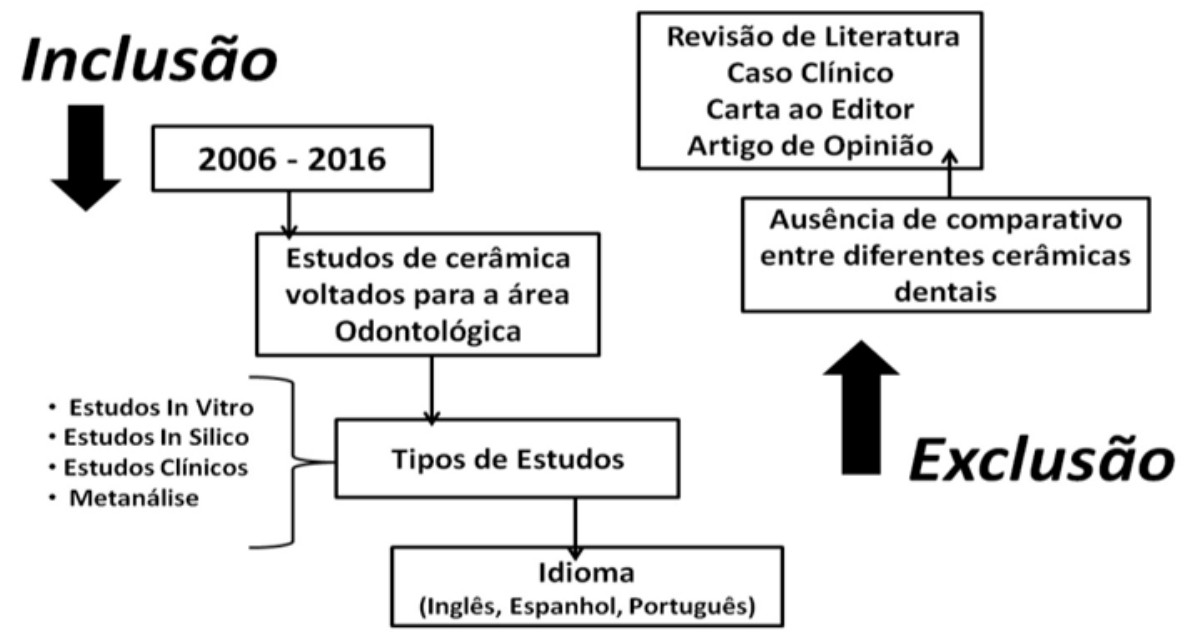

Figura 1. Critérios de inclusão e exclusão utilizados.

A seleção da análise do conteúdo foi realizada com base na leitura de resumos, definindo assim os artigos científicos que foram incluídos e excluídos nesta revisão. Bem como, artigos duplicados em base de dados diferentes foram contabilizado apenas uma vez.

\section{Revisão de liłeratura}

A revisão de literatura será pautada na abordagem sobre cerâmicas odontológicas, o desgaste e longevidade das mesmas.

\section{Cerâmicas Odontológicas}

Devido a incessante busca pela estética, o mercado odontológico, a cada geração, desenvolve sistemas cerâmicos com propriedades diferenciadas para atender as indicações clínicas, com base na Odontologia adesiva ${ }^{4}$. As cerâmicas odontológicas podem ser classificadas como ácido-sensíveis ou ácidoresistentes, de acordo com a sensibilidade ao condicionamento com ácido fluorídrico a $10 \%{ }^{5}$. Com o surgimento de materiais híbridos recentemente, deva ocorrer no futuro mudanças nesta classificação.
Assim as cerâmicas ácido-sensíveis são definidas como materiais sensíveis ao condicionamento com ácido fluorídrico a $10 \%$, ou seja, a ação desde ácido promove a alteração da superfície destas cerâmicas elevando a energia e rugosidade superficial, fatores estes que favorecem ao fenômeno da adesão aos cimentos resinosos, este grupo de cerâmicas é representado pelas feldspáticas, também reforçadas por leucitas e dissilicatos de lítio ${ }^{4,5}$.

A ação do condicionamento ácido somado à aplicação do agente de união, silano, produz altos valores de resistência de união as cerâmicas ácido-sensíveis, pois apresentam elevado conteúdo vítreo na composição que possibilita a ação do condicionamento ácido e favorece a estética ${ }^{4,5,6,7}$.

As cerâmicas acidoresistentes apresentam elevado conteúdo cristalino, ou seja, fase vítrea inexistente ou em pequenas proporções, fazendo com que o condicionamento ácido não promova satisfatórios valores de resistência de união aos cimentos resinosos $^{4,5}$. As cerâmicas à base de alumina e zircônia representam materiais acidoresistentes, esta característica microestrutural promove um excelente desempenho mecânico 5 . 
Na última década muito se questionou sobre a adesão entre as cerâmicas odontológicas e os cimentos resinosos, e pouco abordou-se sobre fratura ou "lascamento" destes materiais. O recente aumento de estudos clínicos que identificaram a fratura da cerâmica levantou a questão de quais os critérios que devem constituir o sucesso ou o fracasso de próteses livre de metal. Assim se faz necessário abordar fatores biológicos, mecânicos e adesivos para se avaliar a taxa de sobrevivência de restaurações cerâmicas ${ }^{8}$.

\section{Desgaste e longevidade dos materiais cerâmicos}

O desgaste destes materiais cerâmicos são ainda muito questionados na literatura, com o surgimento dessa classe de cerâmicas resistentes o desgaste do dente antagonista hígido tem sido observado em alguns estudos, bem como este desgaste pode vir a interferir diretamente na longevidade da peça cerâmica ${ }^{3}$.

Porém, devido a inconsistência de estudos clínicos que apontem a evidência científica desta problemática, os relatos da literatura apontam resultados controversos e ainda não há um fator de associação direta entre o desgaste da estrutura dentária com o material cerâmico. A literatura revela que os estudos sobre este tema estão sujeitos a uma quantidade substancial de variáveis ${ }^{3}$. Testes laboratoriais sistemáticos revelaram que os seguintes fatores influenciam fortemente 0 desgaste: tratamento de superfície, o sistema antagonista e espessura do esmalte ${ }^{2}$.

O tipo de material interefere no desgaste do elemento antagonista, bem como o polimento (tratamento superficial) da peça cerâmica pode favorecer este processo de desgaste ${ }^{10}$. Em 2008, Etman et al. ${ }^{11}$ avaliaram o desgaste do esmalte dentário e diferentes materiais restauradores, observou que o desgaste do esmalte entre restaurações livres de metal foi mais acentuado que as coroas metalocerâmicas.
Estudos apontam que, a técnica de polimento final da coroa pode interferir no desgaste do elemento antagonista, mas não observou-se associação entre o desgaste do esmalte e a rugosidade cerâmica ${ }^{13,14}$. Porém, há relatos que o coeficiente de atrito interfere no desgaste do esmalte dental ${ }^{15,16}$.

A avaliação de materiais cerâmicos e metais em relação ao desgaste dos mesmos e tecidos dentais, observou-se a maior perda de estrutura dental quando o antagonista era uma coroa de cerâmica fedspática reforçada por leucita, seguido pelo dissilicato de lítio, zircônia e aço. Já em relação ao desgaste do material cerâmico o dissilicato de lítio sofreu maiores perdas, durante a simulação de atrição mecânica, que os demais materiais cerâmicos ${ }^{18}$.

Sripetchdanond et al. ${ }^{19}$ e Zandparsa et al. ${ }^{20}$ também afirmam que não há diferença entre os materiais cerâmicos e material restaurador direto (resina composta) para a perda de esmalte do elemento antagonista, sendo ambos resultados de estudos laboratoriais. Mundhe et al. ${ }^{21}$ observaram através de estudo clínico que o desgaste do esmalte na região oclusal durante 12 meses após a cimentação de uma coroa de metalocerâmica como antagonista, foi significativamente maior do que o de uma coroa de zircônia, também oposta ao esmalte natural.

\section{Resultados}

A busca da literatura resultou numa lista de 140 artigos científicos mediante consulta com os descritos: ceramic, longevity, tooth wear. Sendo estes publicados nos últimos 10 anos, nos idiomas inglês, espanhol e português. No total, foram incluídos 13 estudos (FIGURA. 2). Sendo que estes foram avaliados e distribuídos de acordo com os objetivos e os resultados relacionados ao desgaste e logevidade destes materiais, como mostra na TABELA 2. 


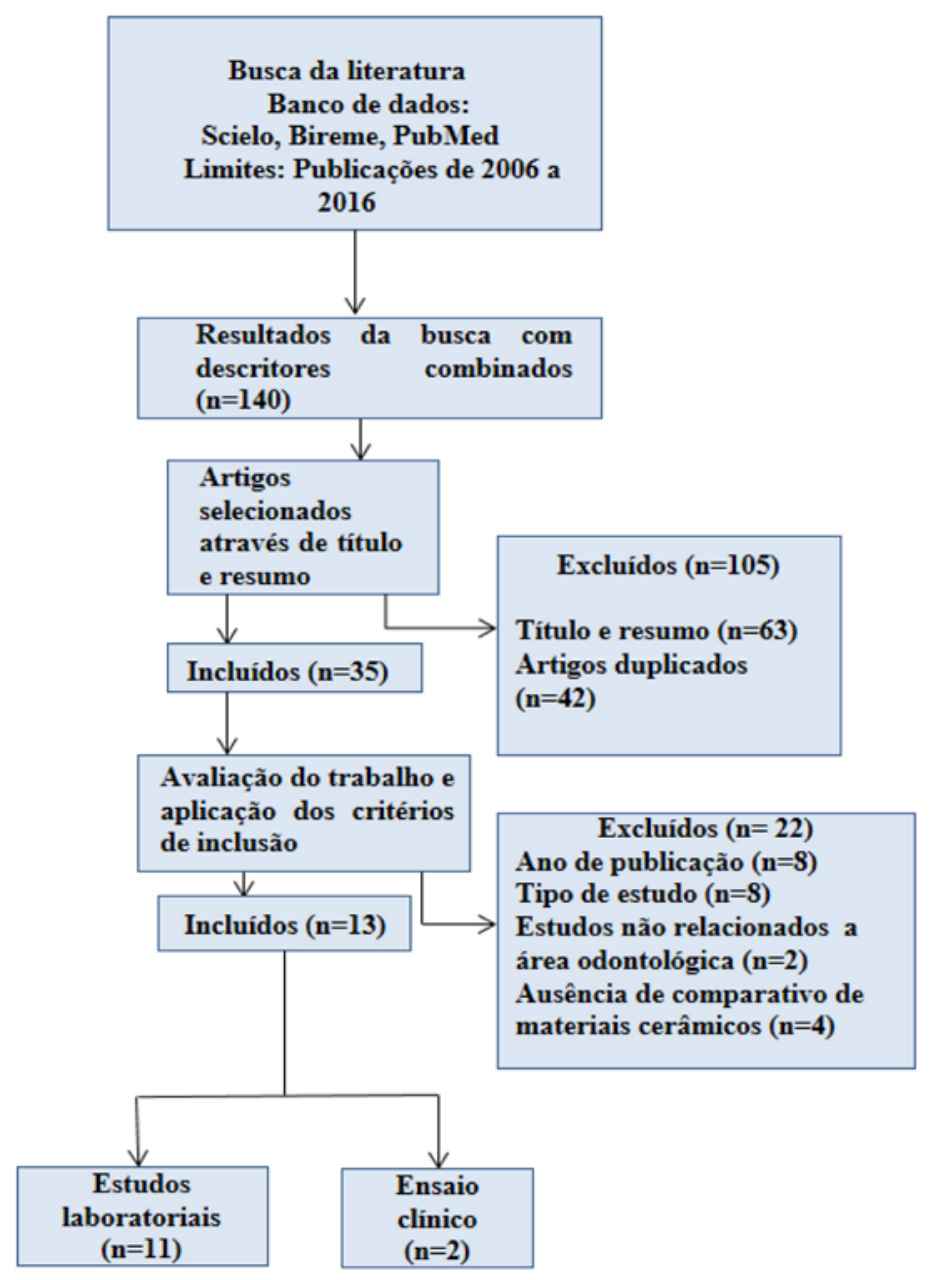

Figura 2. Fluxograma da seleção dos artigos para inclusão na revisão sistemática.

Tabela 2. Distribuição dos objetivos e resultados dos estudos incluídos nesta revisão sitemática.

\begin{tabular}{|c|c|c|}
\hline REFERÊNCIAS & OBJETIVOS & RESULTADOS \\
\hline $\mathrm{CHOl}$ et al. ${ }^{18}$ & $\begin{array}{l}\text { Avaliar os efeitos da } \\
\text { cobertura total de zircônia } \\
\text { de cerâmica pura, o } \\
\text { dissilicato de lítio, cerâmica } \\
\text { vítrea e cerâmica leucita, ou } \\
\text { coroas de aço inoxidável } \\
\text { sobre o desgaste do dente } \\
\text { antagonista principal. }\end{array}$ & $\begin{array}{l}\text { O grupo leucita }(2,670 \pm 1,471 \mathrm{~mm}) \\
\text { apresentou a maior quantidade de desgaste } \\
\text { do dente antagonista, seguido por ordem } \\
\text { decrescente pelo lítio }(2,042 \pm 0,696 \mathrm{~mm}) \text {, } \\
\text { zircônia }(1,426 \pm 0,477 \mathrm{~mm}) \text {, e grupos de } \\
\text { aço ( } 0,397 \pm 0,192 \mathrm{~mm}) \text {. Significa que } \\
\text { perdas de volume em grupos de leucita e o } \\
\text { lítio foram significativamente maiores do que } \\
\text { no grupo de aço (P < } 0,05) \text {. Não foi } \\
\text { observada diferença significativa entre as } \\
\text { perdas de volume médias na zircônia e } \\
\text { grupos de aço (P>0,05). }\end{array}$ \\
\hline CHONG et al. ${ }^{14}$ & $\begin{array}{l}\text { Para investigar o efeito dos } \\
\text { procedimentos laboratoriais } \\
\text { e clínicos para acabamento } \\
\text { de zircônia no desgaste do } \\
\text { esmalte antagonista. }\end{array}$ & $\begin{array}{l}\text { Não houve diferença estatística na perda de } \\
\text { esmalte volumétrica e vertical entre CAR } \\
\text { (Clinicamente ajustada e re-polida), G } \\
\text { (polida em laboratório e vidros) e LP (Polida } \\
\text { em laboratório). CAR produzindo perda de } \\
\text { esmalte estatística e significativamente menos } \\
\text { volumétrica em comparação com CA } \\
\text { (Clinicamente ajustada) e controle e perda } \\
\text { de esmalte estatística e significativamente } \\
\text { menos vertical, em comparação com CA. } \\
\text { Perda de esmalte volumétrica e vertical } \\
\text { foram altamente correlacionados em todos os } \\
\text { grupos. }\end{array}$ \\
\hline
\end{tabular}




\begin{tabular}{|c|c|c|}
\hline REFERÊNCIAS & OBJETIVOS & RESULTADOS \\
\hline D'ARCANGELO et al. ${ }^{17}$ & $\begin{array}{l}\text { Comparar a resistência ao } \\
\text { desgaste de } 2 \text { corpos de } \\
\text { esmalte humano, liga de } \\
\text { ouro, e } 5 \text { cerâmicas } \\
\text { dentárias diferentes, } \\
\text { incluindo um silicato de lítio } \\
\text { e cerâmica reforçada com } \\
\text { zircônia recentemente } \\
\text { introduzida (Celtra Duo). }\end{array}$ & $\begin{array}{l}\text { A profundidade de desgaste }(0,223 \\
\text { milimetros) de liga de ouro era o mais } \\
\text { próximo ao do esmalte humano }(0,217 \\
\text { milímetros), sem diferença significativa ( } P> \\
0,05) \text {. O maior desgaste foi gravado pela } \\
\text { Celtra Duo (desgaste de profundidade = } \\
0,320 \mathrm{~mm}) \text {, que apareceu muito menos } \\
\text { resistente ao desgaste do que a liga de ouro } \\
\text { ou esmalte humano ( } P<05) \text {, e para as outras } \\
\text { cerâmicas testadas não diferiram } \\
\text { estatisticamente em comparação com o } \\
\text { esmalte dental humano. }\end{array}$ \\
\hline ELMARIA et al. ${ }^{10}$ & $\begin{array}{l}\text { Avaliar o desgaste do } \\
\text { esmalte causados por } 3 \\
\text { substratos cerâmicos nas } \\
\text { condições de vidros e } \\
\text { polidos. }\end{array}$ & $\begin{array}{l}\text { O teste One-way ANOVA indicaram que a } \\
\text { perda de altura de esmalte foi } \\
\text { significativamente diferente com material ( } P \\
<.001 \text { ) e condição de superfície (vidrados e } \\
\text { polidos nem lustrados; } P<0,05 \text { ). Ouro, } \\
\text { Finesse polido e All- Ceram polido foram os } \\
\text { menos abrasivos, enquanto IPS- Empress } \\
\text { envidraçada foi o mais abrasivo. Não houve } \\
\text { efeito de interação significativa entre o tipo } \\
\text { de substrato e condição de superfície. } \\
\text { Diferenças significativas foram encontradas } \\
\text { quando R(a), da condição substrato foi } \\
\text { comparado com o desgaste do esmalte ( } P< \\
0,01 \text { ). }\end{array}$ \\
\hline ETMAN et al. ${ }^{11}$ & $\begin{array}{l}\text { Medir quantitativamente o } \\
\text { desgaste dentário e } \\
\text { cerâmica ao longo de um } \\
\text { período de } 2 \text { anos usando } \\
\text { uma técnica de } \\
\text { sobreposição. Foram } \\
\text { utilizados três sistemas } \\
\text { cerâmicos experimentais, } \\
\text { cerâmico prensado a } \\
\text { quente (CE), Procera } \\
\text { AllCeram (PA), e metalo- } \\
\text { cerâmica. }\end{array}$ & $\begin{array}{l}\text { A avaliação quantitativa mostrou mais } \\
\text { desgaste no Procera AllCeram nas áreas de } \\
\text { contato oclusais, enquanto os sistemas } \\
\text { experimentais e metalocerâmica mostrou } \\
\text { menos desgaste. Houve uma diferença } \\
\text { significativa na quantidade de esmalte } \\
\text { desgastado entre todos os tipos de } \\
\text { restaurações ( } P<.05 \text { ). Havia uma diferença } \\
\text { estatisticamente significativa ( } P<0,05 \text { ) na } \\
\text { profundidade média de desgaste entre } \\
\text { todos os sistemas. }\end{array}$ \\
\hline JUNG et al. ${ }^{12}$ & $\begin{array}{l}\text { Avaliar a validade } \\
\text { clínicade coroa com } \\
\text { cobertura total de zircônia, } \\
\text { comparando a capacidade } \\
\text { de desgaste de zircônia } \\
\text { sobre os dentes } \\
\text { antagonistas com a de } \\
\text { porcelana feldspática } \\
\text { odontológica. }\end{array}$ & $\begin{array}{l}\text { Os graus de desgaste dos dentes } \\
\text { antagonistas foram 0,1 } 19 \pm 0,059 \\
\text { milímetros (3) no Grupo } 1 \text { (Porcelana } \\
\text { feldspática), 0,078 } \pm 0,063 \text { milímetros (3) no } \\
\text { Grupo } 3 \text { (Zircônia polida com vidros), e } \\
0,031 \pm 0,033 \text { milímetros (3) no grupo } 2 \\
\text { (Zircônia polida). Há significância estatística } \\
\text { entre o Grupo } 1 \text { e o Grupos } 2 \text { e entre ० } \\
\text { grupos } 2 \text { e } 3 \text {, ao passo que não houve } \\
\text { significância estatística entre o Grupo } 1 \text { e } \\
\text { Grupo } 3 \text {. }\end{array}$ \\
\hline LEE et al. ${ }^{15}$ & $\begin{array}{l}\text { Investigar e comparar o } \\
\text { atrito e desgaste do } \\
\text { esmalte do dente humano } \\
\text { que se opõe a } 2 \text { materiais } \\
\text { restauradores indiretos: } \\
\text { dissilicato de lítio } \\
\text { vitrocerâmica e ouro Tipo III. }\end{array}$ & $\begin{array}{l}\text { O ouro tipo III tinha um coeficiente de atrito } \\
\text { significativamente menor ( } \mathrm{P}=0,009 \text { ) e } \\
\text { causou menos desgaste no esmalte do que a } \\
\text { cerâmica de dissilicato de lítio. } \mathrm{O} \text { esmalte } \\
\text { que se opôs ao dissilicato de lítio } \\
\text { vitrocerâmica apresentaram fissuras, sulcos } \\
\text { de arado, e perda de superfície, o que } \\
\text { indica o desgaste abrasivo como o } \\
\text { mecanismo de desgaste proeminente. Em } \\
\text { comparação, a cicatriz de desgaste do } \\
\text { esmalte antagonista ao ouro Tipo III teve } \\
\text { pequenas manchas de esfregaço aderida à } \\
\text { superfície, o que indica um mecanismo de } \\
\text { desgaste predominantemente adesivo. }\end{array}$ \\
\hline
\end{tabular}




\begin{tabular}{|c|c|c|}
\hline REFERÊNCIAS & OBJETIVOS & RESULTADOS \\
\hline MITOV et al. ${ }^{13}$ & $\begin{array}{l}\text { Avaliar a influência de } \\
\text { diferentes procedimentos de } \\
\text { acabamento sobre o } \\
\text { comportamento de desgaste } \\
\text { de zircônia contra o esmalte } \\
\text { natural. }\end{array}$ & $\begin{array}{l}\text { A rugosidade da superfície foi } \\
\text { significativamente diferente entre os } \\
\text { espécimes polidos, diamond- acabado, e } \\
\text { vidrados cerâmicos (ANOVA, post hoc } \\
\text { Bonferroni p <0,05). Os resultados da } \\
\text { ANOVA one-way indicaram que a técnica de } \\
\text { acabamento afetava significativamente o } \\
\text { desgaste do esmalte (p < } 0,05 \text { ). O teste post } \\
\text { hoc indicaram que os espécimes terminaram } \\
\text { com o diamante grosso causando } \\
\text { significativamente maior desgaste } \\
\text { antagonista do que os polidos. O dióxido de } \\
\text { zircónio polido mostrou o menor desgaste do } \\
\text { esmalte antagonista, com um valor médio de } \\
\text { 171,74 (DP = } 121,68 \text { ), e resultou no } \\
\text { desgaste do esmalte que não foi } \\
\text { significativamente diferente do grupo de } \\
\text { controle de cerâmica de vidro. Nenhuma } \\
\text { correlação linear significativa poderia ser } \\
\text { encontrado entre rugosidade da superfície } \\
\text { pré- teste e desgaste abrasivo. }\end{array}$ \\
\hline MUNDHE et al. ${ }^{21}$ & $\begin{array}{l}\text { Avaliar e comparar o } \\
\text { desgaste do esmalte } \\
\text { oposição esmalte natural, } \\
\text { zircônia e de metal coroas } \\
\text { cerâmicas após } 1 \text { ano. } \\
\text {. }\end{array}$ & $\begin{array}{l}\text { O teste One-way de medidas repetidas } \\
\text { ANOVA foi conduzido para analisar os } \\
\text { dados. Média } \pm \text { SD de desgaste oclusal do } \\
\text { antagonista ao esmalte } 1 \text { ano após a } \\
\text { cimentação de coroas metalocerâmicas foi } \\
69,20 \pm 4,10 \mathrm{~mm} \text { para dentes pré-molares e } \\
179,70 \pm 8,09 \mathrm{~mm} \text { para dentes molares, } \\
\text { enquanto que para coroas de zircônia, que } \\
\text { foi de } 42,10 \pm 4,30 \mathrm{~mm} \text { para dentes pré- } \\
\text { molares e } 127,00 \pm 5,03 \wedge \mathrm{M} \text { para os } \\
\text { dentes molares. O desgaste oclusal do } \\
\text { esmalte natural, opondo esmalte natural foi } \\
\text { 17,30 } \pm 1,88 \mathrm{~mm} \text { na região de pré-molares } \\
\text { e } 35,10 \pm 2,60 \text { mm na região molar. O teste } \\
\text { de Bonferroni post-hoc revelaram que o } \\
\text { desgaste do esmalte oclusal antagonista de } \\
1 \text { ano após a cimentação de uma coroa } \\
\text { metalocerâmica foi significativamente maior } \\
\text { (P }<0,001 \text { ) do que o de uma coroa de } \\
\text { zircônia oposta ou esmalte natural. }\end{array}$ \\
\hline NORDAHL et al. ${ }^{9}$ & $\begin{array}{l}\text { Avaliar a resistência à } \\
\text { fratura de alta translúcidez } \\
\text { (HTZ) e coroas de baixa } \\
\text { translúcida (LTZ) zircônia e } \\
\text { vitrocerâmicos (LDS). }\end{array}$ & $\begin{array}{l}\text { A média de resistências à fraturavariaram } \\
\text { de } 450 \text { a } 3248 \mathrm{~N} N \text { no grupo LTZ, } 438 \mathrm{~N} \text { a } \\
3487 \mathrm{~N} \text { no grupo HTZ, } 1030 \text { e } 1431 \mathrm{~N} \text { para } \\
\mathrm{N} \text { no grupo de LDS. A carga de ruptura de } \\
\text { HTZ e LTZ das coroas eram iguais. A carga } \\
\text { de ruptura de coroas de zircônia tetragonal } \\
\text { policristalina estabilizada com ítria foi } \\
\text { significativamente maior do que as coroas } \\
\text { LDS (p = 0,000). Dois tipos de fraturas foram } \\
\text { registrados; fratura completa e parcial de } \\
\text { crack -like. O tipo de crack fratura ocorreu } \\
\text { mais frequentemente em todos os grupos, } \\
\text { exceto nos grupos LTZ mais grossas ( } 1,0 \text { mm } \\
\text { e } 1,5 \text { mm). De acordo com este estudo, não } \\
\text { há diferença na força entre coroas de } \\
\text { zircônia de alta ou baixa translucidez. Na } \\
\text { mesma espessura, a força de coroas de } \\
\text { zircônia foi significativamente maior do que } \\
\text { a do dissilicato de lítio de cerâmica vítrea. }\end{array}$ \\
\hline
\end{tabular}




\begin{tabular}{|c|c|c|}
\hline REFERÊNCIAS & OBJETIVOS & RESULTADOS \\
\hline PARK et al. ${ }^{16}$ & $\begin{array}{l}\text { Avaliar o desgaste de } 2 \\
\text { corpos de antagonistas } \\
\text { para 3,concepção e } \\
\text { computer-aided fabricação } \\
\text { assistida por computador ( } \\
\text { CAD / CAM) cerâmicas de } \\
\text { zircônia contornoanatômico } \\
\text { e porcelana de } \\
\text { revestimento, quando se } \\
\text { opor esmalte humano } \\
\text { natural. }\end{array}$ & $\begin{array}{l}\text { As observações SEM de cada grupo revelou } \\
\text { bolhas finas e superfícies porosas no grupo } \\
\text { de cerâmica feldspática Noritake, enquanto } \\
\text { o grupo Zirkonzahn Y- TZP polido, grupo } \\
\text { Acucera Y- TZP e Wieland grupo Y- TZP } \\
\text { tinham superfícies lisas. A rugosidade da } \\
\text { superfície de Zirkonzahn } Y \text { - TZP após } \\
\text { coloração e envidraçamento foi } \\
\text { significativamente maior do que a de } \\
\text { quaisquer outros grupos ( } P<.01 \text { ). O dente } \\
\text { oposto do grupo Zirkonzahn } Y-T Z P \text { polido } \\
\text { demonstrou menos desgaste ( } 1,11 \pm 0,51 \\
\text { mm }{ }^{3} \text { ), enquanto Zirkonzahn } Y-T Z P \text { com } \\
\text { coloração e vidros produziu o maior } \\
\text { desgaste do esmalte ( } 3,07 \pm 0,98 \text { mm }{ }^{3} \text { ) } \\
\text { entre os grupos de zircônia. O grupo de } \\
\text { cerâmica feldspática Noritake mostrou o } \\
\text { desgaste do dente antagonista } \\
\text { significativamente maior do que outros } \\
\text { grupos ( }<0,05 \text { ). }\end{array}$ \\
\hline SRIPETCHDANOND et al. ${ }^{19}$ & $\begin{array}{l}\text { Investigar o desgaste do } \\
\text { esmalte em oposição à } \\
\text { cerâmica dentária e resina } \\
\text { composta. }\end{array}$ & 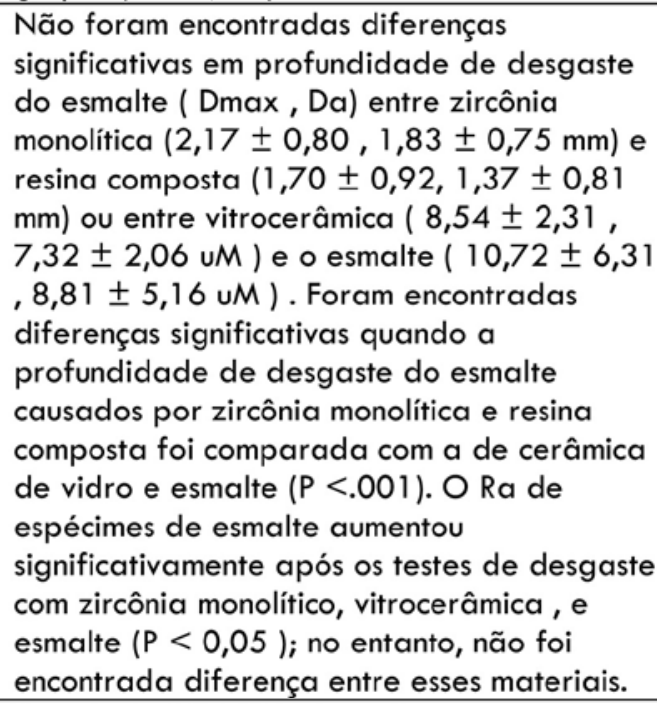 \\
\hline ZANDPARSA et al. ${ }^{20}$ & $\begin{array}{l}\text { Comparar o desgaste dos } \\
\text { sistemas cerâmicos } \\
\text { avançados contra } \\
\text { antagonistas de esmalte } \\
\text { humano. }\end{array}$ & $\begin{array}{l}\text { Depois de } 125.000 \text { ciclos de carregamento } \\
\text { bidireccional, a perda média de oposição } \\
\text { volume de esmalte para os discos de esmalte } \\
\text { no grupo controle foi de } 37,08 \mathrm{~mm}(3), 0 \\
\text { valor médio mais baixo para IPS e.max Press } \\
\text { sistema foi } 39,75 \mathrm{~mm}(3) ; 40,58 \mathrm{~mm}(3) \text { para } \\
\text { IPS e.max CAD; } 45,08 \text { uM (3) para Noritake } \\
\text { Super porcelana sistema de EX - } 3 \text {; e } 48,66 \\
\text { mm (3) para o sistema Lava Além disso } \\
\text { Zirconia. Sem estaticamente foram } \\
\text { encontradas diferenças significativas entre os } \\
\text { grupos na oposição perda de volume do } \\
\text { esmalte (P = 0,225) ou na oposição ao } \\
\text { esmalte perda de altura (P = 0,149). Em } \\
\text { termos de opostos perda de altura esmalte, } \\
\text { sistema de Lava Além disso Zirconia } \\
\text { apresentou o menor valor médio de } 27,5 \\
\text { mm. O valor médio para o sistema e.max } \\
\text { CAD IPS foi } 27,91 \text { m; } 29,08 \text { mm para o } \\
\text { esmalte de controlo; } 33,25 \text { mm para os IPS } \\
\text { e.max sistema de Imprensa; e } 34,75 \text { mm } \\
\text { para o sistema de Noritake Super porcelana } \\
\text { EX - } 3 \text {. }\end{array}$ \\
\hline
\end{tabular}




\section{Discussão}

Mostra-se importante a análise do desgaste do esmalte humano versus um antagonista também com esmalte, a fim de obterem-se valores médios deste desgaste, para então verificar se determinado material cerâmico apresenta realmente valores significativos para questionamento como mostra nos estudos de Mundhe et al. ${ }^{21}$ e Sripetchdanond et al. ${ }^{19}$

Com base nos estudos revisados, pode-se afirmar que dentre os materiais cerâmicos, a zircônia foi o que apresentou a menor quantidade de desgaste do dente antagonista; como mostra na pesquisa laboratorial de Choi et al. ${ }^{18}$ que compararam a zircônia com outros materiais cerâmicos, leucita (apresentando maior desgaste) seguido pelo dissilicato de lítio. Jung et al. ${ }^{12}$ que compararam a porcelana feldspática e dois grupos de zircônia com diferentes técnicas de polimento, também apresentando-se a última menos danosa.

Dentre os materiais totalmente cerâmicos, a zircônia mostra-se mais benéfica em relação a coroas metalocerâmicas opostas ao esmalte natural, ou seja, conforme os achados da literatura, a zircônia promove menor desgaste do elemento antagonista. ${ }^{21}$ Outros materiais como o ouro, aço, resina composta foram avaliados em alguns estudos comparando-os a materiais cerâmicos, quanto ao desgaste do dente antagonista; Choi et al. ${ }^{18}$ obtiveram o resultado de que o aço causa menos desgaste que a cerâmica ao dente natural.

As ligas áuricas são materiais que ocasionam um baixo nível de desgaste do esmalte dental, aproximando-se do desgaste promovido pelo próprio tecido em questão, conforme o estudo de D'arcangelo et al. ${ }^{15}$ Sripetchdanond et al. ${ }^{19}$ que avaliaram a resina composta, não encontrou diferenças significativas em profundidade de desgaste ao esmalte com relação as cerâmicas vítrea e a zircônia.

Os estudos analisados, não deixaram evidente qual seria o fator causador específico do desgaste do dente natural antagonistas frente à uma coroa cerâmica. Quanto a longevidade dos materiais cerâmicos, apontam o dissilicato de lítio como a cerâmica mais degradada frente a um antagonita natural, conforme mostra o estudo de Choi et al. ${ }^{16}$.
A análise dos artigos desta revisão evidencia a escassez de estudos com os maiores níveis de evidência científica, como estudos clínicos para a avaliação do desgaste de materiais cerâmicos, havendo a predominância dos estudos laboratoriais. Isso se deve provavelmente pelas complexidades metodológicas que envolvem o delineamento e desenvolvimento desses tipos de estudos; como também a ação de fatores externos para realizar tais ensaios clínicos. A literatura revela que os estudos sobre este tema estão sujeitos a uma quantidade substancial de variáveis. ${ }^{3}$

Os achados por meio dos artigos desta revisão sistemática mostram a complexidade de estudar o comportamento destes materiais cerâmicos, pois esperava-se que quanto maior o grau de resistência cerâmica, maior seria o desgaste do elemento dental antagonista, visto que há uma diferença na microestrutura destes materiais. Fatores como textura superficial, área da restauração cerâmica na arcada dentária, processamento do material, polimento final, podem influenciar na quantidade de desgaste do dente natural antagonista ao material cerâmico e na logevidade do próprio material são questões que devem ser observados em estudos futuros para auxiliar a seleção destes materiais pelo cirurgião-dentista.

Novos estudos com alto grau de evidência científica, ou seja, estudos clínicos randomizados devem ser realizados para investigar o desgaste do esmalte dental com relação ao antagonista com coroa livre de metal, assim obter dados significativos em relação ao desgaste e longevidade de materiais cerâmicos.

\section{Conclusão}

A partir dos achados obtidos nesta revisão sistemática, bem como das limitações ao realizar a mesma, pode-se afirmar que o desgaste do elemento dental antagonista (esmalte) parece ser maior quando utiliza-se uma cerâmica ácido-sensível em relação a uma cerâmica acidoresistente; já quanto a longevidade destes materiais cerâmicos - dissilicato de lítio apresenta a maior perda de material. 


\section{Conflitos de interesses}

Nenhum conflito financeiro, legal ou político envolvendo terceiros (governo, empresas e fundações privadas, etc.) foi declarado para nenhum aspecto do trabalho submetido (incluindo mas não limitando-se a subvenções e financiamentos, conselho consultivo, desenho de estudo, preparação de manuscrito, análise estatística, etc).

\section{Referências}

1. Della Bona A, Kelly JR. The clinical success of all-ceramic restorations. J Am Dent Assoc. 2008;139(4):8-13.

2. Heintze SD, Cavalleri A, Forjanic M, Zellweger G, Rousson $V$. Wear of ceramic and antagonista--a systematic evaluation of influencing factors in vitro. Dent Mater. 2008;24(4):43349. doi: $10.1016 /$ i.dental.2007.06.016

3. Hmaidouch R, Weigl P. Tooth wear against ceramic crowns in posterior region: a systematic literature review. Int J Oral sci. $2013 ; 5(4): 183-90$. doi: $10.1038 /$ ijos.2013.73

4. Silva $A M T$, de Figueiredo $V M G$, de Farias $A B L$, Brito NMSO, Catão MHCV, Queiroz JRC. Estratégias de cimentação em restaurações livres de metal: uma abordagem sobre tratamentos de superfície e cimentos resinosos. Revista Bahiana de Odontologia. 2016;7(1):49-57. doi: 10.17267/2238-2720revbahianaodonto.v7i1.666

5. Bottino MA, Faria R, Valandro LF. Percepção estética em próteses livre de metal em dentes naturais e implantes. São Paulo: Artes Médicas; 2009.

6. Elsaka SE. Bond strength of novel CAD/CAM restorative materials to self-adhesive resin cement: the effect of surface treatments. J Adhes Dent. 2014;16(6):531-40. doi: 10.3290/i.jad.a33198

7. Ramos NC, Campos TM, Paz IS, Machado JP, Bottino $M A$, Cesar PF et al. Microstructure characterization and scg of newly engineered dental ceramics. Dent Mater. 2016;32(7):870-8. doi: 10.1016/i.dental.2016.03.018

8. Anusavice KJ. Standardizing failure, success, and survival decisions in clinical studies of ceramic and metal-ceramic fixed dental prostheses. Dent Mater. 2012;28(1):102-11. doi: 10.1016/i.dental.2011.09.012

9. Nordahl N, Vult Von Vteyern P, Larsson C, Fracture strength of ceramic monolithic crown systems of different thickness. J Oral Sci. 2015;57(3):255-61. doi: 10.2334/iosnusd.57.255

10. Elmaria A, Goldstein G, Vijayaraghavan T, Legeros RZ, Hittelman EL. An evaluation of wear when enamel is opposed by various ceramic materials and gold. J Prosthet Dent. 2006;96(5):345-53. doi: 10.1016/i.prosdent.2006.09.002
11. Etman MK, Woolford M, Dunne S. Quantitative measurement of tooth and ceramic wear: in vivo study. Int J Prosthodont. 2008;21(3):245-52.

12. Jung YS, Lee JW, Choi YJ, Ahn JS, Shin SW, Huh JB. A study on the in-vitro wear of the natural tooth structure by opposing zirconia or dental porcelain. J Adv Prosthodont. 2010;2(3): 111 -5. doi: 10.4047/iap.2010.2.3.111

13. Mitov G, Heintze SD, Walz S, Woll K, Muecklich F, Pospiech P. Wear behavior of dental y-tzp ceramic against natural enamel after different finishing procedures. Dent Mater. 201 2;28(8):909-18. doi: 10.1016/i. dental.2012.04.010

14. Chong BJ, Thangavel AK, Rolton SB, Guazzato $M$, Klineberg IJ. Clinical and laboratory surface finishing procedures for zirconia on opposing human enamel wear: a laboratory study. J Mech Behav Biomed Mater. 2015;50:93103. doi: $10.1016 /$ i.jmbbm.2015.06.007

15. Lee A, Swain M, He L, Lyons K. Wear behavior of human enamel against lithium disilicate glass ceramic and type iii gold. J Prosthet Dent. 2014;1 12 (6):1399-405. doi: 10.1016/i.prosdent.2014.08.002

16. Park JH, Park S, Lee K, Yun KD, Lim HP. Antagonist wear of three cad/cam anatomic contour zirconia ceramics. J Prosthet Dent. 2014;1 11 (1):20-9. doi: 10.1016/i. prosdent.2014.08.002

17. D'Arcangelo C, De Angelis F, Rondoni GD, Vaninni L. Wear properties of dental ceramics and porcelains compared with human enamel. J Prosthet Dent. 2016; 1 15(3):350-5. doi: 10.1016/i.prosdent.2015.09.010

18. Choi JW, Bae IH, Noh TT, Ju SW, Lee TK, Ahn JS et al. Wear of primary teeth caused by opposed all-ceramic or stainless steel crowns. J Adv Prosthodont. 2016;8(1):43-52. doi: $\underline{10.4047 / \text { iap.2016.8.1.43 }}$

19. Sripetchdanond J, Leevailoj C. Wear of human enamel opposing monolithic zirconia, glass ceramic, and composite resin: an in vitro study. J Prosthet Dent. 2014;112(5): 1141 50. doi: $10.1016 /$ i.prosdent.2014.05.006

20. Zandparsa R, El Huni RM, Hirayama H, Johnson MI. Effect of different dental ceramic systems on the wear of human enamel: An in vitro study. J Prosthet Dent. 2016;155(2):2307. doi: 10.1016/i.prosdent.2015.09.005

21. Mundhe K, Jain V, Pruthi G, Shah N. Clinical study to evaluate the wear of natural enamel antagonist to zirconia and metal ceramic crowns. J Prosthet Dent. 2015;114 (3):358-63. doi: 10.1016/i.prosdent.2015.03.001 